\title{
Concurrent outbreaks of dengue, chikungunya and Zika virus infections - an unprecedented epidemic wave of mosquito-borne viruses in the Pacific 2012-2014
}

A Roth (adamr@spc.int) ${ }^{1}$, A Mercier ${ }^{1}$, C Lepers ${ }^{1}$, D Hoy ${ }^{1}$, S Duituturaga ${ }^{1}$, E Benyon ${ }^{1}$, L Guillaumot ${ }^{2}$, Y Souarès ${ }^{1}$

1. Secretariat of the Pacific Community, New Caledonia

2. Institut Pasteur de Nouvelle-Caledonie, Noumea, New Caledonia

Citation style for this article:

Roth A, Mercier A, Lepers C, Hoy D, Duituturaga S, Benyon E, Guillaumot L, Souarès Y. Concurrent outbreaks of dengue, chikungunya and Zika virus infections

- an unprecedented epidemic wave of mosquito-borne viruses in the Pacific 2012-2014. Euro Surveill. 2014:19(41):pii=20929. Available online: http://www.

eurosurveillance.org/ViewArticle.aspx?Articleld=20929

Since January 2012, the Pacific Region has experienced 28 new documented outbreaks and circulation of dengue, chikungunya and Zika virus. These mosquito-borne disease epidemics seem to become more frequent and diverse, and it is likely that this is only the early stages of a wave that will continue for several years. Improved surveillance and response measures are needed to mitigate the already heavy burden on island health systems and limit further spread to other parts of the world.

Since January 2012, the Pacific is experiencing a high burden of mosquito-borne disease due to concurrent epidemics of dengue, chikungunya and Zika virus infections. So far over 120,000 people have been reported to be affected, a figure that is likely to substantially underestimate the real numbers due to underreporting. For as long as there has been data available from the Region (i.e. 40 years), this epidemic wave of mosquitoborne viruses with 28 new mosquito-borne viral outbreaks $(n=25)$ and circulation $(n=3)$ documented since January 2012 (18 Dengue virus (DENV) serotype 1-4, 7 chikungunya virus and 3 Zika virus infection outbreaks, respectively) is unprecedented (Table) [1-3]. We here present an overview of the surveillance and epidemiology of these mosquito-borne disease epidemics in the Pacific Region, to help facilitate response measures that are needed to mitigate the already heavy burden on island health systems and to limit further spread to other parts of the world.

\section{Surveillance of mosquito-borne viruses in the Pacific Region}

The Pacific Public Health Surveillance Network (PPHSN) is a voluntary network of countries, territories and organisations created in 1996. It is dedicated to the promotion of public health surveillance and response to health emergencies in the Pacific Region. It covers 22 Pacific Island countries and territories (hereafter referred to as the Pacific Region) with a population of 10.6 million inhabitants [4]. The network services include the timely exchange of information on outbreak-prone disease through PacNet, an email list with around 680 health professionals, and diagnostic support through a network of laboratories for identification and verification of pathogens.

In 2010, the Pacific Syndromic Surveillance System was introduced in the PPHSN. It monitors four syndromes and aims at improved early warning to complement routine notifiable disease notification systems that generally are not timely and seldom used for regional surveillance purposes in the Pacific Region. The Syndromic Surveillance system is under development and currently includes sentinel reporting from primary healthcare or hospital sites in all countries [5]. Manifest dengue, chikungunya and Zika virus infections have a similar initial clinical presentation and may be reported as any of the first three of the following four monitored syndromes: (i) acute fever and rash, (ii) prolonged fever, (iii) influenza-like illness and (iv) diarrhoea. Due to similar initial clinical features to the three mosquito-borne diseases, concurrent measles epidemics and leptospirosis pose diagnostic challenges in the Region.

There is a need for timely, reliable and detailed data on mosquito-borne virus outbreaks and circulation of the viruses in the Pacific Region. To obtain a comprehensible overview of the present epidemiological picture, several sources of information are used. Further to PacNet, syndromic and laboratory-based surveillance, event-based surveillance (mainly media and personal communications with health professionals) and surveillance by-proxy (reports of exported cases to neighbouring countries) [6] are also important. To facilitate better risk assessments and efficiency of data dissemination, this data is visualized in a recently launched interactive map available from: www.spc.int/phd/epidemics. The map, updated weekly, provides the region for the first time with a dynamic real-time picture of the current epidemic situation. 


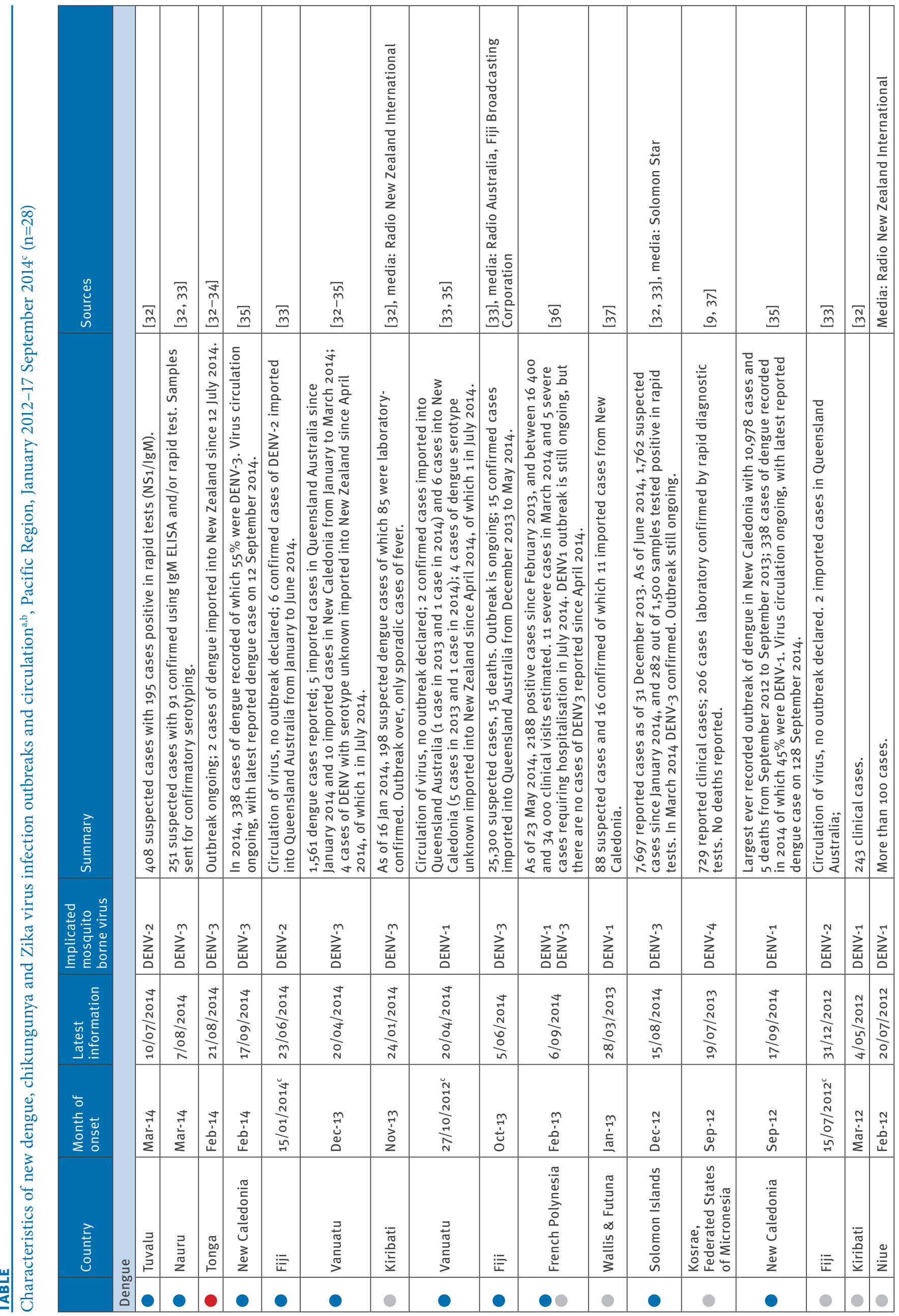




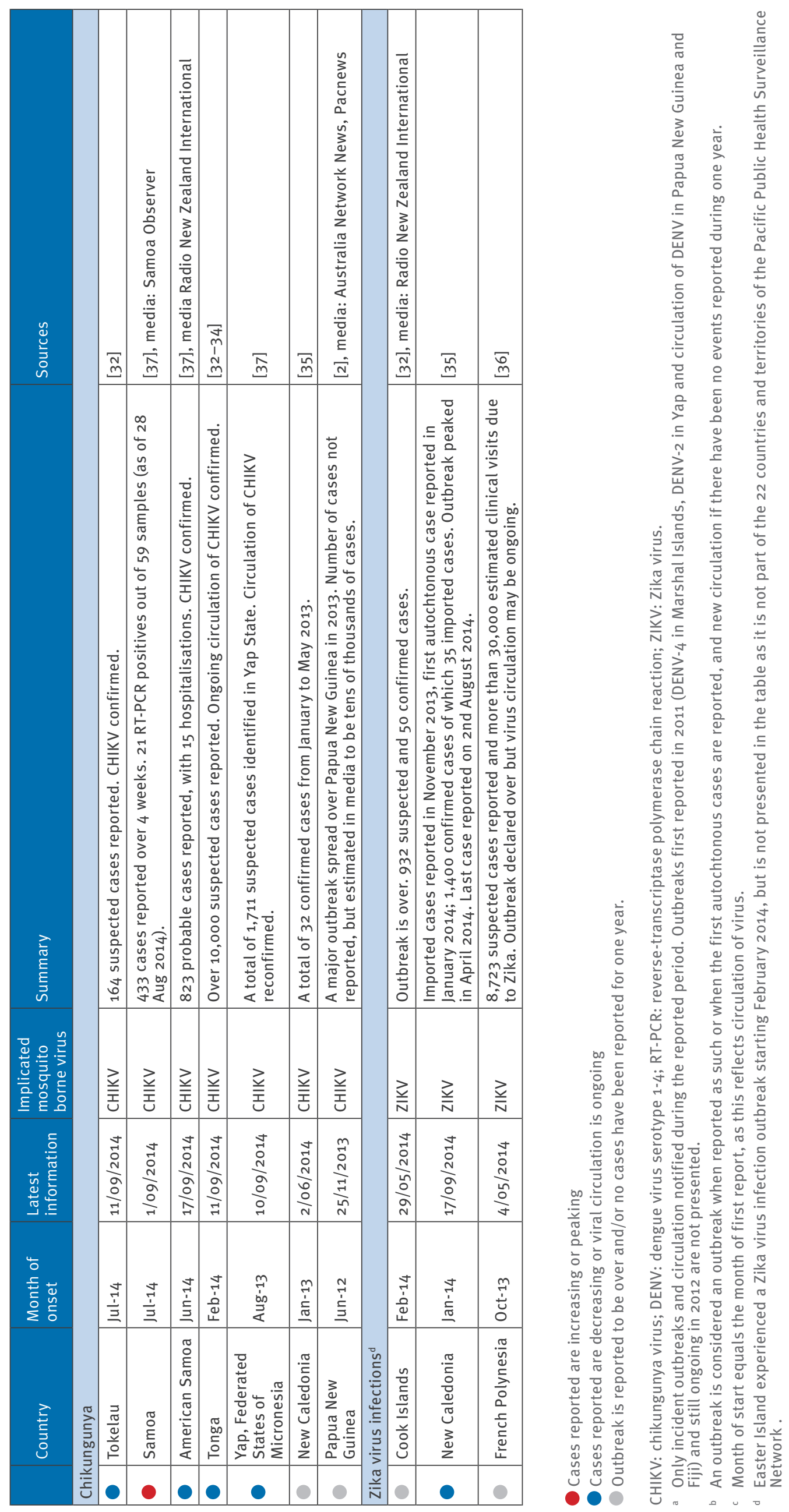


The epidemiology of mosquito-borne viruses in the Pacific Region

Mosquito-borne virus diseases in the Pacific Region have a distinct epidemiology due to small populations scattered over thousands of tropical and sub-tropical islands on both sides of the equator in relative geographic isolation, together with (nowadays) significant people's mobility and thereby exposure to circulating arboviruses through the airline networks of the AsiaPacific region (Figure 1).

Between January 2012 and 17 September 2014, a total of 28 new mosquito-borne viral outbreaks $(n=25)$ and circulation $(n=3)$ were documented: 18 DENV 1-4 outbreaks (2012: 7; 2013: 6; 2014: 5), 7 chikungunya virus (CHIKV) (2012: 1; 2013: 2; 2014: 4) and 3 Zika virus infection outbreaks (2012: 0; 2013: 1; 2014: 2), respectively.

Looking at the first semester of 2014 , the number of outbreaks and circulating mosquito-borne viruses seem to be increasing (Figure 2). During the same period, DENV-3 became the dominating dengue virus, and since Zika virus started to spread in the end of 2013, there was concurrent circulation of DENV-1,-2 and -3, CHIKV and Zika virus (Table, Figure 2)

\section{Dengue}

The epidemic pattern of dengue in the Pacific Region has typically presented in form of sporadic or rare epidemics rather than a hyperepidemic/endemic pattern, with one dominating serotype sweeping across the islands every 3 to 5 years, and with varying duration of circulation in different islands largely depending on population size [1,7-8]. During 2012, there were outbreaks of all four serotypes of DENV documented for the first time during one year (Figure 2) [1]. DENV-1 was the dominating serotype in 2012 and beginning 2013, causing the largest documented dengue outbreak ever in New Caledonia, with 10,978 confirmed cases and 5 deaths from September 2012 to September 2013. Since 2012 there have only been reports of one outbreak with DENV-2 and -4 respectively: DENV- 2 recently caused an outbreak in Tuvalu with 408 suspected cases ( $4 \%$ of the population) and DENV-4 caused a large outbreak in Kosrae in September 2012 to March 2013 with 729 clinical cases ( $11 \%$ of the population) (Table) [9]. Furthermore there have been reports of new circulation of DENV-2 in Fiji. (Table) After having been absent in the region for 18 years, DENV- 3 has after the reintroduction in 2012, become the dominating DENV in the region with five ongoing outbreaks, one of them in Fiji, with 25,300 suspected cases and 15 deaths (Table, Figure 1) $[1,10]$.

\section{FIGURE 1}

Map of newly reported dengue, chikungunya and Zika virus infection outbreaks or new virus circulation ${ }^{\mathrm{a}}$, Pacific Region ${ }^{\mathrm{b}}$, January 2012-17 September 2014c $(\mathrm{n}=28)$

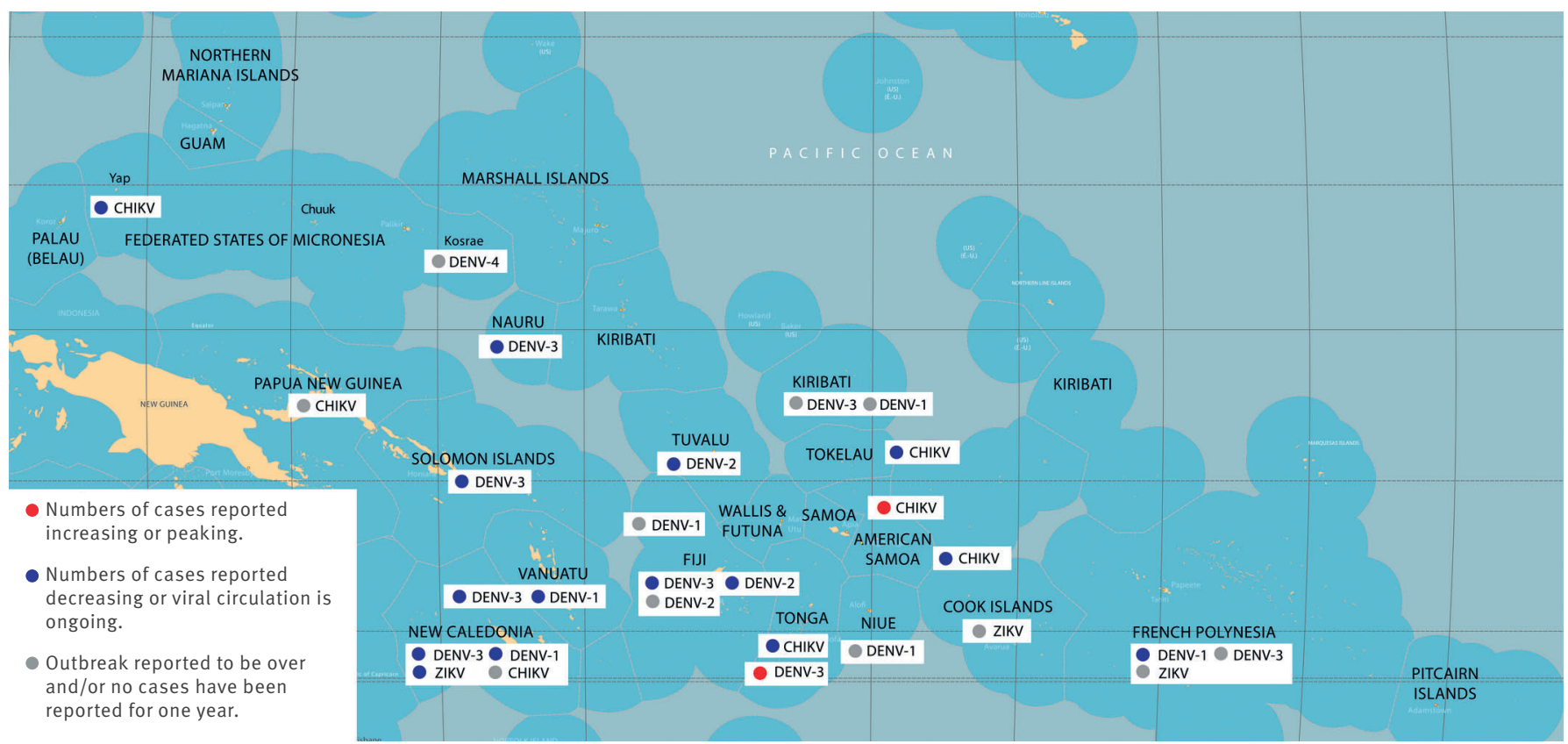

CHIKV: chikungunya virus; DENV: dengue virus serotype 1-4; ZIKV: Zika virus.

a Only incident outbreaks and virus circulation reported during the period. Outbreaks first reported in 2011 (DENV-4 in Marshal Islands, DENV-2 in Yap and circulation of DENV in Papua New Guinea and Fiji) and still ongoing in 2012 are not presented.

b The 22 Pacific Island countries and territories that are core members of the Pacific Public Health Surveillance Network and referred to as the Pacific Region.

Real-time interactive map with current epidemiological situation and alerts is available from: www.spc.int?phd/epidemics 


\section{Chikungunya}

After being reported in the Pacific for the first time in a small tightly controlled outbreak in New Caledonia in 2011 [11], CHIKV is currently becoming established in the Region (Figure 1, Table) [2]. In Papua New-Guinea in 2012-13, the largest epidemic in the Region so far with estimated (though poorly documented) tens of thousands of cases, was caused by the East Central South African (ECSA) lineage of the virus [2]. The Asian lineage of the virus was responsible for the outbreak in Yap State (2013-14) [12] and also in New Caledonia (2013) where CHIKV re-emerged in the middle of a large DENV-1 epidemic and caused a small outbreak, similar to the 2011 outbreak (Table) [13]. Phylogenetic analyses of the CHIKV involved in the outbreaks in Tonga, Samoa and American Samoa are not yet available. Due to the on-going geographic expansion of Aedes albopictus in the Pacific region (Figure 3 ), virus genotype monitoring is a crucial aspect of surveillance.

\section{Zika virus infections}

After the first documented Pacific Zika outbreak in Yap in 2007 [14], the Asian lineage of the virus reappeared in French Polynesia in October 2013, and has since caused large outbreaks in New Caledonia (1,400 confirmed cases), Cook Islands (over 900 cases) and Easter Island that is not part of the PPHSN (Figure 1,

\section{FIGURE 2}

Incidence and aetiology of newly reported mosquito-borne virus outbreaks and circulation ${ }^{\mathrm{a}}$ by semester ${ }^{\mathrm{b}}$, Pacific

Region, January 2012-17 September $2014^{c}(n=28)$

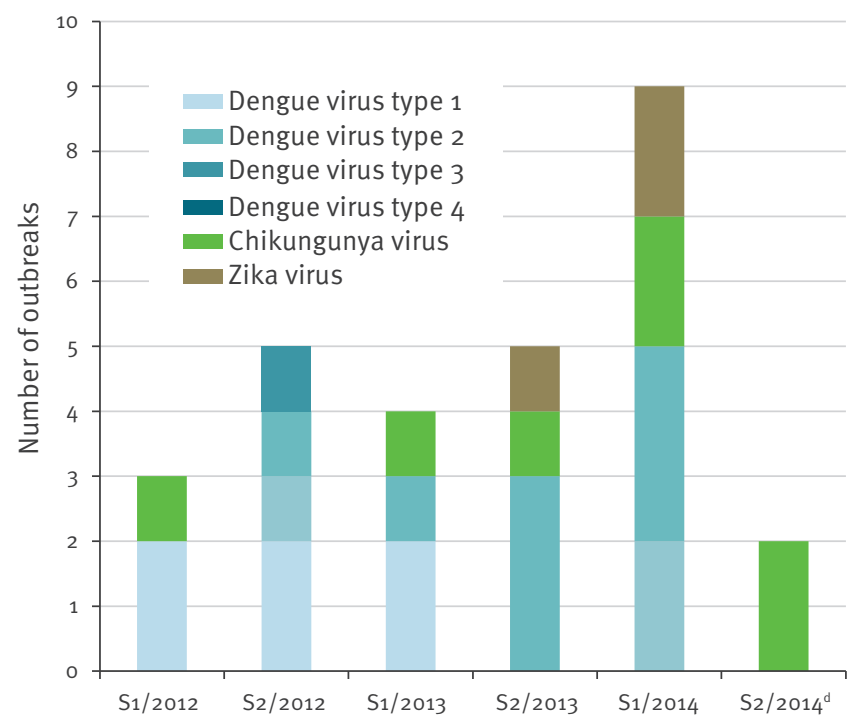

S: semester.

a An outbreak is considered an outbreak when reported as such, and new circulation of virus if there has been no event with the same virus reported during one year previously.

$S_{1}$ includes the months from January to June and $S_{2}$ the months from July to December.

Outbreaks or circulation that started before January 2012 or after 17 September 2014 are not presented in this graph to allow observation of a possible trend over time.

d Semester 2 in 2014 is not complete, and only includes reports from two full months out of six.
Table) [3]. In French Polynesia, extrapolation of the 8,746 suspect cases reported by the sentinel surveillance network allows to infer that over 30,000 medical consultations were due to the spread of Zika virus throughout the archipelago. Between November 2013 and February 2014, increased incidence of neurological complications, including 42 cases of Guillain-Barré syndrome, was a unique and worrying feature of the French Polynesia outbreak that warrants further studies [3].

\section{Discussion and Conclusions}

Burden on the Pacific countries and territories Mosquito-borne outbreaks are greatly exacerbating the pre-existing burden that Pacific Island primary healthcare systems face. If not managed well, the epidemic wave may threaten societies broadly, affecting trade, tourism and work force beyond the direct morbidity and mortality toll [2]. During the chikungunya outbreak in Reunion Island, one third of the around 800,000 inhabitants were infected, peaking at more than 47,000 estimated cases in one week, with estimated productivity loss of $€ 17.4$ million (range $€ 6$ to $€ 28.9$ million) and medical costs of $€ 43.9$ million that were met by the French state [15-17]. Much of the burden on the Pacific Region of the concurrent epidemics of all three diseases covered here is unknown and further studies are warranted, especially on co-infection and the effect of sequential infection with different viruses.

Zika virus disease, generally reported to have a mild clinical presentation, was associated with neurological complications during concurrent Zika virus disease and dengue epidemics in French Polynesia $[3,18]$. The Pacific Region may be particularly vulnerable to communicable diseases due to isolation and immunologically naive populations, but also due to rates of non-communicable disease, such as obesity, diabetes and cardiovascular disease, that are among the world's highest on some islands [19].

\section{The risk for further spread}

While there have been efforts to improve surveillance in the Pacific over the past two decades, it is not likely that the extent of the current increase in diversity and frequency of mosquito-borne virus outbreaks in the Pacific can be explained solely by improved surveillance systems. In the island setting of the Indian Ocean, the largest documented CHIKV outbreak lasted four years (2004-2007) [15]. Therefore, considering also the previous dengue outbreaks in the Pacific Region [1-2] and the diversity of the current outbreaks, it seems likely that the Pacific Region is in the early stages of an epidemic wave for the three mosquito-borne viruses that started in $\mathbf{2 0 1 2}$ and is likely to continue for several years.

The risk for further spread in the Pacific Region is high for several reasons. Firstly, it is likely that there is little immunity to these diseases, as DENV-3 had not been 
circulating in the Region since 1995 [1] and prior to the current wave, CHIKV and Zika virus occurrence in the Pacific was limited to two documented outbreaks [11, 14]. Secondly, competent vectors present in the Region, mainly $A e$. aegypti and Ae. albopictus, but also other local mosquitoes such as Ae. polynesiensis or Ae. hensilli are known to transmit these viruses (Figure 3 ) [20]. These species have been incriminated in DENV transmission on epidemiological and/or experimental (laboratory infections) grounds. Several of them are confirmed or strongly suspected vectors of CHIKV and Zika viruses [21]. Thirdly, large population mobility and airline travel facilitate the spread [22].

Vector control capacity in the Pacific Region is often limited or insufficient [11]. At present, there is no ongoing entomological surveillance system targeting vectors of dengue and other arboviruses established in the Region except in New Caledonia, Fiji and French Polynesia. The current knowledge about mosquito distribution in the other countries and territories is based on data collected during entomological investigations in surveys from the second half of the 2oth century and from some more recent surveys [20]. Interestingly, the three viruses involved in this epidemic wave are not broadly mosquito-borne, but specifically Aedes (Stegomyia)-borne.

The cause of the recent increase in mosquito-borne disease in the Pacific Region is largely unknown, but is in line with a global increase of emerging diseases, and likely driven by a combination of socio-economic, environmental and ecological factors [23].

The continuous challenges of dengue and chikungunya [24] and more recently Zika virus infections [25]

\section{FIGURE 3}

Map of the known distribution of Aedes (Stegomyia) mosquitoes, vectors of dengue and possible vectors of chikungunya and Zika viruses, Pacific Region as of beginning October 2014

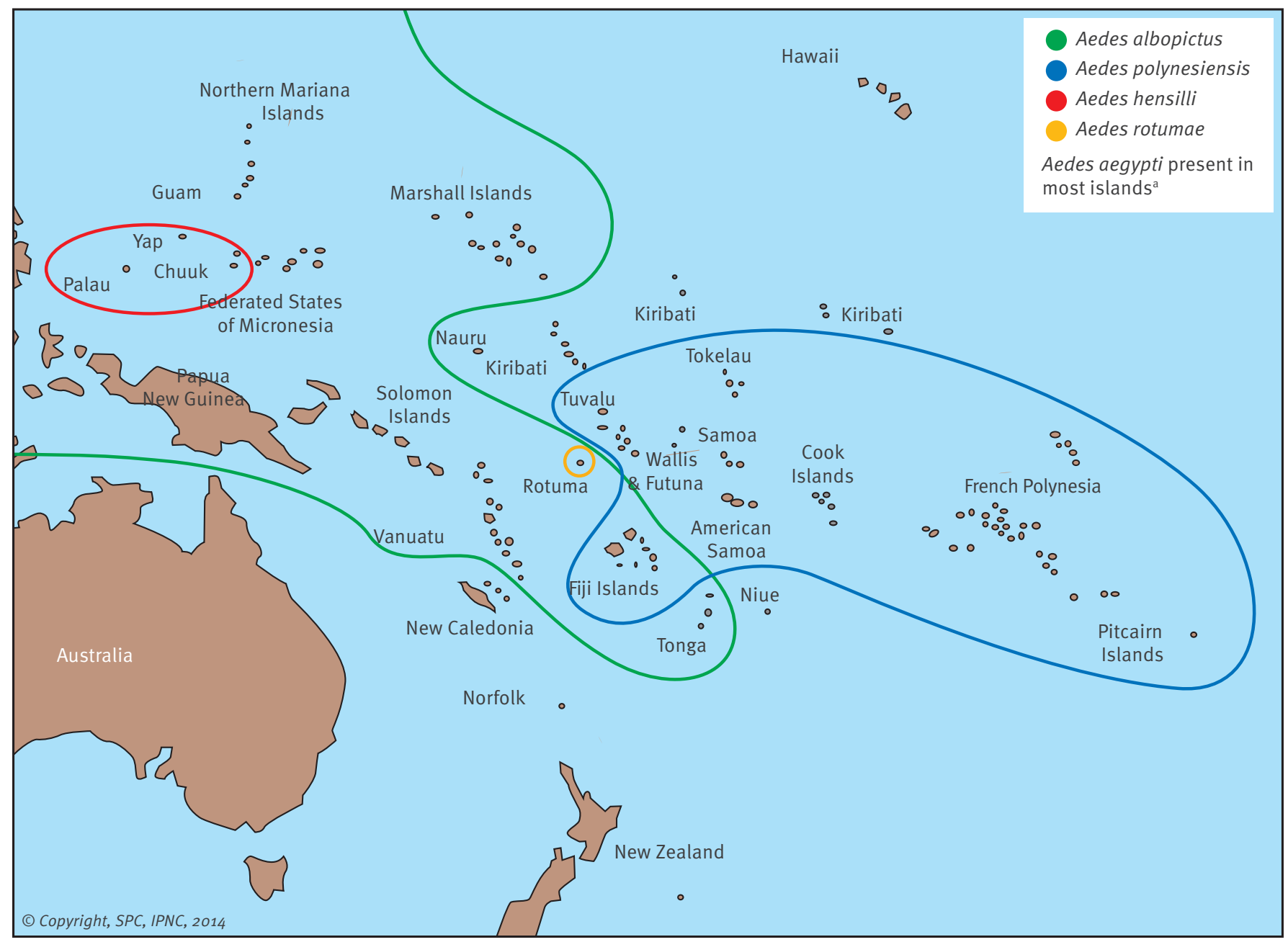

a Aedes aegypti (not represented on the map) is present throughout most of the region including North Queensland. It is absent from the rest of Australia, New Zealand, Hawaii, Futuna and some other remote islands, and it seems to be currently displaced by Ae. albopictus in many locations (e.g. Papua New Guinea and Solomon Islands).

The known or strongly suspected distributions of other vectors are as follows (not exhaustive): Ae. scutellaris (Indonesia; Northern Australia, Papua New Guinea); Ae. marshallensis (Marshall Islands; Western Kiribati; Kosrae; Pohnpei); Ae. hebrideus (Papua New Guinea; Solomon Islands; Vanuatu); Ae. cooki (Niue, Vava'u Group, Tonga); Ae. tongae (Ha'apai Group, Tonga); Ae. tabu (Tongatapu group, Tonga); Ae. kesseli (Niua group, Tonga); Ae. pseudoscutellaris (Fiji). [25] 
for Europe, the re-emergence of dengue in Japan [26], and the first-time chikungunya transmission in the Americas [27], show that these viruses pose a threat to any country with competent vectors. The epidemiology of mosquito-borne viruses in the Pacific may be changing. There are close links between the several European overseas countries and territories in the Pacific Region and Europe and the United States [28]. Considering the extensive airline travel between the Pacific Region and other parts of the world where the viruses have not yet been established e.g. Europe and the United States, it should be of international interest to stay informed of the spread of the current Pacific Region wave of mosquito-borne viruses and to support surveillance and control efforts $[2,23,29]$.

Examples of response from PPHSN partners to the epidemic situation include the provision of support and capacity building to Pacific Islands in surveillance, outbreak investigation and response, and mass-gathering surveillance. The Pacific Outbreak Manual is also being updated to include specific response guidelines for the three viruses [30].

To further enhance surveillance and response measures, Pacific Directors and Ministers of Health have shared the current risk assessment, and the upcoming Pacific International Health Regulations meeting will focus on mosquito-borne diseases. Island primary healthcare-based systems have difficulties to cope with high caseloads and there is a need for early multidisciplinary preparedness and response to face larger outbreaks adequately [2].

\section{Acknowledgements}

All PPHSN partners should be acknowledged for the hard work that has contributed to this overview. In particular we wish to acknowledge: the Pacific Island countries and territories and their health professionals for country reports and updates on PacNet and to the Pacific Syndromic Surveillance reports; the WHO Suva for managing the Pacific Syndromic Surveillance reports; all international and regional partner organisations that assist PPHSN member countries in surveillance and outbreak investigations and capacity building thereof; national laboratories for primary diagnosis and sampling and laboratories serving as regional references or assisting in first diagnostic confirmation of mosquito-borne disease - Fiji Centre for Communicable Disease Control (FCDCC) Mataika House, Guam Public Health Laboratory (GPHL), Institut Pasteur New Caledonia (IPNC), Institut Louis Malardé (ILM) Tahiti French Polynesia, CDC Atlanta US, CDC Puerto Rico, Hawaii State Laboratory (HSL), Fort Collins Laboratory USA, Queensland University of Technology (QUT) Australia, Queensland Health \& Forensic Scientific Services (QHFSS) Australia; and the surveillance units reporting imported cases of mosquito-borne disease - La Direction des Affaires Sanitaires et Sociales de la Nouvelle-Calédonie New Caledonia, Queensland Health Australia notifiable conditions data and Institute of Environmental Science and Research (ESR) New Zealand dengue report.

Conflict of interest

None declared.
Authors' contributions

$A R, Y S, C L, D H$ conceived the idea of the paper. $A R, A M, C L$, $S D$ and $E B$ contributed to data gathering and cleaning. $A R, C L$ and $A M$ conducted the analysis. LG gathered and compiled all vector data and analysis. AR and $A M$ drafted the first draft, and all

authors commented and agreed upon the final manuscript.

\section{References}

1. Singh N, Kiedrzynski T, Lepers C, Benyon EK. Dengue in the Pacific--an update of the current situation. Pacific Health Dialog. 2005;12(2):111-9.

2. Roth A, Hoy D, Horwood PF, Ropa B, Hancock T, Guillaumot L, et al. Preparedness for threat of chikungunya in the pacific. Emerging Infect Dis. 2014;20(8). http://dx.doi.org/10.3201/ eid2008.130696

3. Musso D, Nilles EJ, Cao-Lormeau VM. Rapid spread of emerging Zika virus in the Pacific area. Clin Microbiol Infect. 2014 http://dx.doi.org/10.1111/1469-0691.12707

4. Les populations du Pacifique 2013. [Pacific Island Populations 2013]. French. Nouméa, 2013. Statistics for Development Division, Secretariat of the Pacific Community. Available from: http://www.spc.int/sdd/index.php/en/downloads/ doc_download/738-2013-pacific-population-poster

5. Kool JL, Paterson B, Pavlin BI, Durrheim D, Musto J, Kolbe A. Pacific-wide simplified syndromic surveillance for early warning of outbreaks. Global Public Health. 2012;7(7):670-81. http://dx.doi.org/10.1080/17441692.2012.699536

6. Lau CL, Weinstein P, Slaney D. Dengue surveillance by proxy: travellers as sentinels for outbreaks in the Pacific Islands. Epidemiol Infect. 2013;141(11):2328-34. http://dx.doi. org/10.1017/So950268813000058

7. Dupont-Rouzeyrol M, Aubry M, O’Connor O, Roche C, Gourinat AC, Guigon A, et al. Epidemiological and molecular features of dengue virus type-1 in New Caledonia, South Pacific, 2001-2013. Virol J. 2014;11:61. http://dx.doi. org/10.1186/1743-422X-11-61

8. Morens DM. Dengue fever: a prevention summary for Pacific health workers. Pacific Health Dialog. 1996;3(1):240-52.

9. Centers for Disease Control and Prevention (CDC). Dengue outbreak--Federated States of Micronesia, 2012-2013. MMWR. Morbidity and mortality weekly report. 2013;62(28):570-3.

10. Cao-Lormeau VM, Roche C, Musso D, Mallet HP, Dalipanda T, Dofai A, et al. Dengue virus type 3, South Pacific Islands, 2013. Emerg Infect Dis. 2014;20(6):1034-6. http://dx.doi. org/10.3201/eid2006.131413

11. Dupont-Rouzeyrol M, Caro V, Guillaumot L, Vazeille M, D'Ortenzio E, Thiberge JM, et al. Chikungunya virus and the mosquito vector Aedes aegypti in New Caledonia (South Pacific Region). Vector Borne Zoonotic Dis. 2012;12(12):1036-41. http://dx.doi.org/10.1089/vbz.2011.0937

12. Nhan TX, Claverie A, Roche C, Teissier A, Colleuil M, Baudet JM, et al. Chikungunya virus imported into French polynesia, 2014. Emerg Infect Dis. 2014;20(10):1773-4. http://dx.doi. org/10.3201/eid2010.141060

13. Dupont-Rouzeyrol M, O’Connor O. Phylogénie moléculaire des Arbobirus en Nouvelle-Calédonie. Institut Pasteur de Nouvelle-Calédonie: La Recherche: Rapport d'activité 2013. [Molecular Phylogeny of Arboviruses in New Caledonia. Pasteur Institute of New Caledonia; Annual report 2013. p 24. Doc. $n^{\circ} 156 / 2014$-IPNC/DG of 25 June 2014. Noumea, 2013.] p 24. Doc. $n^{\circ}$ 156/2014-IPNC/DG du 25 juin 2014. Nouméa, 2013. Available from: http://www.institutpasteur.nc/wp-content/ uploads/2013/07/Rapport-2013-IPNC-RECHERCHE-n\%C2\%Bo156-26-juin-2014.pdf

14. Duffy MR, Chen TH, Hancock WT, Powers AM, Kool JL, Lanciotti RS, et al. Zika virus outbreak on Yap Island, Federated States of Micronesia. N Engl J Med. 2009;360(24):2536-43. http:/l dx.doi.org/10.1056/NEJMoao805715

15. Renault P, Balleydier E, D’Ortenzio E, Baville M, Filleul L. Epidemiology of Chikungunya infection on Reunion Island, Mayotte, and neighboring countries. Med Mal Infect. 2012;42(3):93-101. http://dx.doi.org/10.1016/j. medmal.2011.12.002

16. Lagacherie P. [Coverage of the chikungunya epidemic on Reunion Island in 2006 by the French healthcare system]. Med Trop (Mars). 2012;72 Spec No:97-8.

17. Soumahoro MK, Boelle PY, Gauzere BA, Atsou K, Pelat C, Lambert B, et al. The Chikungunya epidemic on La Reunion Island in 2005-2006: a cost-of-illness study. PLoS Negl 
Trop Dis. 2011;5(6):e1197. http://dx.doi.org/10.1371/journal. pntd.0001197

18. Oehler E, Watrin L, Larre P, Leparc-Goffart I, Lastere S, Valour $F$, et al. Zika virus infection complicated by Guillain-Barre syndrome - case report, French Polynesia, December 2013. Eurosurveill. 2014;19(9). pii: 20720.

19. Ng M, Fleming T, Robinson M, Thomson B, Graetz N, Margono C, et al. Global, regional, and national prevalence of overweight and obesity in children and adults during 19802013: a systematic analysis for the Global Burden of Disease Study 2013. Lancet. 2014;384(9945):766-81. http://dx.doi. org/10.1016/S0140-6736(14)60460-8

20. Guillaumot L, Ofanoa R, Swillen L, Singh N, Bossin HC, Schaffner F. Distribution of Aedes albopictus (Diptera, Culicidae) in southwestern Pacific countries, with a first report from the Kingdom of Tonga. Parasit Vectors. 2012;5:247. http://dx.doi.org/10.1186/1756-3305-5-247

21. Ledermann JP, Guillaumot L, Yug L, Saweyog SC, Tided M, Machieng P, et al. Aedes hensilli as a Potential Vector of Chikungunya and Zika Viruses. PLoS Negl Trop Dis 2014 8(10): e3188. http://dx.doi.org/10.1371/journal.pntd.0003188

22. Tatem AJ, Huang Z, Das A, Qi Q, Roth J, Qiu Y. Air travel and vector-borne disease movement. Parasitology. 2012;139(14):1816-30. http://dx.doi.org/10.1017/ So031182012000352

23. Jones KE, Patel NG, Levy MA, Storeygard A, Balk D, Gittleman $\mathrm{JL}$, et al. Global trends in emerging infectious diseases. Nature. 2008;451(7181):990-3. http://dx.doi.org/10.1038/nature06536

24. Chretien JP, Linthicum KJ. Chikungunya in Europe: what's next? Lancet. 2007;370(9602):1805-6. http://dx.doi.org/10.1016/ S0140-6736(07)61752-8

25. European Centre for Disease Prevention and Control (ECDC). Rapid risk assessment: Zika virus infection outbreak, French Polynesia. 14 Feb 2014. Stockholm:, ECDC; 2014.

26. DENGUE - JAPAN: (SAITAMA) [Internet]. International Society for Infectious Diseases. 2014 [cited 2014-09-08]. Available with archive number: 20140828.2731079 from: http://www. promedmail.org/.

27. Staples JE, Fischer M. Chikungunya virus in the Americas-what a vectorborne pathogen can do. N Engl J Med. 2014;371(10):887-9. http://dx.doi.org/10.1056/NEJMp1407698

28. Jones J, Gastellu-Etchegorry M, Stenz FK, Baudon C, Bloem SJ, Bondonneau M, et al. Epidemiology, surveillance and control of infectious diseases in the European overseas countries and territories, 2011. Eurosurveill. 2011;16(29). pii: 19923.

29. Kuehn BM. World leaders push to prepare for global threats. JAMA. 2014;311(12):1189-90. http://dx.doi.org/10.1001/ jama.2014.2272

30. The Pacific Outbreak Manual. Pacific Public Health Surveillance Network (PPHSN). February 2014. Available from: http://www. spc.int/phs/PPHSN/Publications/Pacific_Outbreak_Manual_ wersion1-2.pdf

31. Guillaumot L. Arboviruses and their vectors in the Pacific-status report. Pac Health Dialog. 2005;12(2):45-52.

32. World Health Organization, West Pacific Region (WPRO). Emerging disease surveillance and response. Division of Pacific Technical Support. Weekly Pacific Syndromic Surveillance Report. Fiji: WPRO; 2014. Available from: http:// www.wpro.who.int/southpacific/programmes/communicable diseases/disease_surveillance_response/page/en/indexz. html

33. Queensland Government. Queensland Health. Queensland notifiable conditions data. Last updated: 14 Oct 2014. Brisbane: Queensland Health; 2014.Available from: http:// www.health.qld.gov.au/ph/cdb/sru_data.asp

34. Institute of Environmental Science and Research Ltd (ESR). Dengue weekly updates. Porirua, New Zealand. For details, contact ESR (Institute of Environmental Science and Research Ltd) (ange.bissielo@esr.cri.nz)

35. La direction des affaires sanitaires et sociales de NouvelleCalédonie (DASS). [Department of Health and Social Affairs] Veille sanitaire. French. Nouméa, 2014. [Accessed 17 Sep 2014]. Available from : http://www.dass.gouv.nc/portal/page/ portal/dass/observatoire_sante/veille_sanitaire/

36. Bulletin de surveillance et veille sanitaire en Polynésie français - Bureau de veille sanitaire. [Public Health Surveillance and Monitoring in French Polynesia - Public Health Surveillance Office]. French. Accessed 17 Sep 2014. Available from: http:// www.spc.int/phs/PPHSN/Surveillance/Routine_reports.htm

37. PacNet country reports. For details in PacNet report archives, contact the Focal Point of the Pacific Public Health Surveillance Coordinating Body (FocalPointPPHSNCB@spc. intくmailto:FocalPointPPHSNCB@spc.int») 